\title{
Education, Globalization, Cultural Diversity and a Revised Human Development Index for the Caribbean Region: Findings \& Policy Implications
}

\author{
Ian S. McGowan \\ University of Technology, Jamaica
}

\begin{abstract}
Up to now, the Caribbean region was lacking of a statistical model to sufficiently measure its human capital. A three pronged regression model of the human development index was proposed considering the variables of globalization and cultural diversity. Two of the three hypotheses failed rendering the globalization index not significant but showing that the variable of cultural diversity was highly significant in explaining human development in the region.
\end{abstract}

Keywords: Cultural diversity, globalization, CARICOM

\section{Introduction}

Caribbean economies have been searching for an appropriate model to measure their human development and to promote sustainable development in the region, especially in the postindependence period. With increasing vulnerabilities, the region faces growing multidimensional poverty having experienced a persistent low growth and erosion of human development gains over the past decades (Clarke, 2016). Available data show that real gross domestic product (GDP) growth for the Caribbean region averaged 2.03 percent between 1971 and 2013, as compared to 3.57 percent for Least Developed Countries and 5.99 percent for developing countries in Asia. In pursuit of sustainable development, the region has long recognized some of the primary human development related constraints and challenges it faces, to included limited human resources compounded by high levels of migration of skilled individuals out of the region (Bárcena, 2018). The region also recognized the economic growth is insufficient on its own for lifting and keeping people out of poverty. Thus human development measures to target and address some of the key sources of vulnerability and deprivation and to strengthened adaptive capabilities as in the areas of education and skills training across the region, are of critical importance.

Human development is the process of expanding the range of choices (Kovacevic, 2019), so there is no doubt in the fact that the human capital across the Caribbean region, rather than physical, plays a major role in increasing the rate of economic growth in each of the member countries. In the economics, the human development index (HDI) is used as a basic quantitative assessment of human capital (Sagar, 1998). A comprehensive index, the HDI characterizes the level of human development in a country. The index is inherent in the measurement of a country's achievement in terms of health and longevity, education and actual income of its citizens (Yakunina, 2015; Manliv, 1992). Literacy and enrolment in formal education are the main indicators in the construction of the education achievement index (Narayana, 2006).

A region with a history of colonialism and current exposure to some of the central dilemmas of globalization such as socio-economic inequality and environmental precarity (Brissett, 


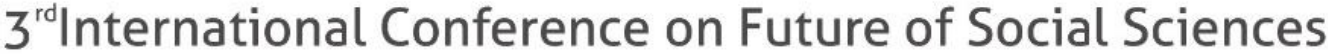

2018), the Caribbean community began to engage in education for social transformation since the 1990s as one its crucial parts of the regional integration movement. From the inception of this movement, the narrative has always maintained the focus on people as central to the process of bringing the Caribbean together and it is vital - if this is to be attained - that an effective functional framework for education and human resource development be constructed (Jules, 2001). The diversity in the region comes in the form of its geography, its people, its governments, its economy and its culture (Vinat, 2003). Through this region, one can see the lasting impact colonization has had and how different the experience for each island had been. Several studies have linked the colonization experience of Caribbean countries to their present day institutions and individual economic performances (Acemoglu et al, 2001; Bruhn et al, 2012; Michalopoulus et al, 2013; Dippel et al, 2018). European colonists had a profound influence on the region's politics, economy and institutions (Dippel et al, 2018). Dippel et al (2018) further explained that this history persisted in to the former colonies through their constitutions, language, education system, ethnic composition, as well as the economic models they followed. Two major ethnic groups emerged in Guyana and Trinidad \& Tobago (T\&T) while five major ethnic groups formed in Suriname (Mc Letchie, 2013). In the case of T\&T, for example, after slavery was abolished in 1838, Africans moved to and settled in urban centers while persons from India who were recruited as indentured workers to replace African slaves were settled in the proximity of the plantations with restrictions on their movement (Bisram, 2015). In studying the region, one can appreciate the mixture of African, European and Native cultures that create the tapestry of Caribbean life. Even though the region is currently globalizing itself through organizations such as CARICOM (Caribbean Community), each island still struggles to prosper and sustain their people. Several studies have been undertaken to establish the statistical relationship between a country's ethnic diversity and its levels of human development, economic development and economic performance (Basci, 2017; Churchill et al, 2020). Studies on the effect of globalization on spurring human development in developed and developing countries have also been undertaken (Sabi, 2007; Muhammed et al, 2010). The relationship between economic liberalization, cultural diversity, human development and quality of people's lives in the CARICOM region however, has not been examined rigorously though. The current HDI index doesn't provide for this examination.

CARICOM is a set of small island development states (SIDS), and there is a mixed evidence on the state of human development in the SIDS (Herbert, 2019). The OECD (2018) finds that human development indicators lag behind those of other developing countries. Example, when using the UN (United Nations) Human Development Index (HDI), two fifths of SIDS have a low or medium levels of development. However, Palanivel (2018) finds that human development in the SIDS is better than in other developing countries, but that long term progress by the SIDs is relatively low compared to other groups. Herbert, 2019) and Kunzel et al (2018) suggest this limitation in the understanding of the development levels such as human development in SIDS is caused by the lack of data. This can mean that databases are completed with "approximations based on assumptions, and alternative assumption could have produced a different

approximations" (Herbert, 2019; Briguglio, 2016). The lack of data on SIDS means that they are often not included in data sets (Herbert, 2019; Briguglio, 2018b).

It is generally considered that human development is the most important aspect for the prosperity and sustained growth of any country (Ullaha et al,2017). So this is an appropriate 
time to empirically analyze the possible impact of globalization policies on human development in the CARICOM region.

Reflecting the possible impact of globalization and effects of this cultural diversity across the Caribbean region on human development and in an attempt to include additional human development data more specific to a SID such CARICOM, this paper is therefore proposing a revised human development index GHDI (or dependent variable) to include the main areas (or independent variables) of gross national income, the education index, the globalization index and the respective country's cultural diversity index. We begin with a background of CARICOM, then an examination of research literature to define the four independent variables followed by a definition of the regression model of the GHDI.

\section{CARICOM}

The economies of the CARICOM are undergoing a process of economic reform in which market-based policies, including trade liberalization, are key components of a new development strategy. With an original goal of economic integration in 1975, powerful new forces since 1990s began to shape its relationship with the global economy (Nogueira, 1997). These forces include the rapid process of globalization, and the formation of new, powerful trading blocs in the Western Hemisphere. The original thirteen member countries of CARICOM have a combined population of 5.6 million people and a GDP of approximately US\$12.5 billion in 1992. Per capita income, except for Guyana, is comparable and/or superior to the average for Latin America; the Bahamas and Barbados have the first and second highest per capita income in the region. In the area of education, the region continues drive the modernization of secondary education across the member countries using a single secondary high set of syllabus and assessment system.

\section{Variables Of The GHDI Model}

\subsection{The Index of Gross National Income per capita (GNI)}

The World Bank uses GNI to classify countries according to levels of development. According to Ocampo (2012), Caribbean economies are characterized by differences in GNI and is a key measure of disparities among the economies. Caribbean policy makers recognize that growth in GNI is a key plank of development and acknowledge that sustained growth in GNI requires high growth rates over a long period of time (James, 2012). In Lyare (2006), the causal relationship between education and development in three Caribbean countries-Barbados, Jamaica, and Trinidad and Tobago — using annual time series data from 1964 to 1998 was studied. The empirical results show that in both the short and long run, the evidence suggests that GNI is driving education in all three countries. In this sense, we build our quantitative regression model of the GHDI by regarding GNI as a contributory factor of measuring human development.

\subsection{The Education Index $(E D)$}

While the impacts of inequitable distribution of GDP in the Caribbean region are the most obvious focus of the discussion on the subject for the region's policy makers, the inequitable distribution of education can have an insidious impact by changing the balance of access to 
opportunities for the citizens in the region (Sagar, 1998). The ED index indicates educational attainment measuring average school life expectancy of children of school age and the mean years of schooling of the adult population. In the Bailey (2009) study of education attainment data from eleven of the CARICOM member countries, it was shown that a disproportionately high percentage of both the males and female populations in five (5) of the countries, that is more than $50 \%$, had only primary level education and were therefore not well equipped for engagement in the paid workforce. Education throughout the CARICOM has likewise been deeply affected by past and present socio-economic challenges in the region. Much of the colonial enterprise destroyed indigenous social systems and with them, the type of education and learning that supported them (Brissett, 2018). So the education index is included in our quantitative regression model of the GHDI.

\subsection{Globalization Index $(G L O B A L)$}

Globalization is a process that erodes national boundaries, integrates national economies, cultures, technologies and governance, and produces complex relations of mutual interdependence (Gygli, 2018). in (Huh et al, 2019), the globalization indices of 158 economies over the period 2006-2014 were studied to evaluate the possible effects of globalization. The results showed that although globalization promotes economic growth, it may worsen income inequality. High income countries benefit most in that the positive effect of globalization on economic growth is strongest among them than on other income groups, and they experience a less pronounced widening of income inequality. Kim (2014) however studied the effects of regionalism on economic development in the 217 economies (including CARICOM, the European and African Unions). The study found that (a) in general, regionalism pursued by countries via their respective regional organizations was found to have no significant independent effect on the economic development, and (b) regardless of regionalism, the international economic variables such as globalization and terms of trade, as well as domestic variables such as population growth, urbanization and ethnic composition were found to have significant impact on economic development. We therefore include the index of globalization in our quantitative regression model of the GHDI.

\subsection{Cultural Diversity Index (CULTURAL)}

Caribbean societies are inescapably heterogeneous. The Caribbean has long been an area where some people live next to others who are remarkably distinct (Premdas, 1995). To understand how peoples in the Caribbean cohere into cultural communities, how they are different and separate, how they act in solidarity and individually, one may look at the diverse bases on which they have tended to define themselves (Premdas, 2011). But is there a statistical relationship between (ethnic) fractionalization and an economy's level of human development? Bacsi (2017) using economic and demographic data of 155 economies established a pattern of correlation between economic development and ethnic or cultural fractionalization (considering only language and cultural traits). Patsiurko (2019) collected 1985-2000 cultural diversity and economic data for a set of OECD countries. The study found that ethnic fractionalization was more closely associated with economic performance than other types of fractionalization. These results quantitatively support the idea that multiculturality being a benefactor for human development, hence we include the index of cultural diversity in our quantitative regression model of the GHDI. 


\section{DERIVING A QUANTITATIVE REGRESSION MODEL OF THE GHDI}

$$
\begin{aligned}
& \mathrm{Y}=G N I+E D+C U L T U R A L+\varepsilon \\
& \mathrm{Y}=G N I+E D+G L O B A L+\varepsilon \\
& \mathrm{Y}=G N I+E D+C U L T U R A L+\text { GLOBAL }+\varepsilon
\end{aligned}
$$

Where $Y$ is the GHDI

Three versions of the quantitative GHDI model are proposed. According to the first version (v1) of the model, human development is statistically explained by the gross national income per capita, the education index and the cultural index considering the error $\mathcal{E}$. The second version (v2) of the proposed model, human development is statistically explained by the gross national income per capita, the education index and the globalization index considering the error $\mathcal{E}$. The third version (v3) of the proposed model, human development is statistically explained by the gross national income per capita, the education index, the cultural index and the globalization index considering the error $\mathcal{E}$.

\section{AIM OF THE STUDY AND HYPOTHSIS}

In correspondence with the quantitative model of the GHDI, our research aims at validating the hypothesized quantitative GHDI model (one or more of the versions), which implies measuring the respective GHDI variables and verifying the following hypotheses:

In addition to gross national income and education index

$\mathrm{H}_{1}$. Cultural diversity influences the level of human development

$\mathrm{H}_{2}$. Globalization processes influence the level of human development

$\mathrm{H}_{3}$. Cultural diversity together with globalization processes influence the level of human development

The validations would confirm evidence of a relationship between globalization and/or cultural diversity and the levels of human development in the CARICOM region.

\section{Construction of the GHDI Index}

\subsection{Index Composition}

In this paper, we will focus on the following indices, which, from our point of view, reflect the level of human capital, namely Human Development Index (HDI) - the gross national income per capita index (GNI), the education index, the cultural diversity index and the globalization index. Table 1 reports on dimensions, indicators and data sources of these indexes. 
Index

Globalization

\section{GNI}

Education

Cultural

Diversity

HDI

Dimension
KOF Globalization
Index
A decent standard of
living
Knowledge

Cultural

fractionalization

Long and healthy life

Knowledge

A decent standard of living

\section{Indicators}

Average of the de facto and de jure Global Index GNI per capita (PPP \$)

Expected years of schooling

Mean years of schooling

Structural distances

between spoken languages (or linguistic similarities)

Life expectancy at birth

Expected years of schooling

Mean years of schooling

GNI per capita (PPP \$)

\section{Data Source}

KOF Swiss

Economic Institute

UN Development

Program

UN Development

Program

UN Development

Program

Fearon (2003).

Pages 218-219

UN Development

Program

UN Development

Program

UN Development

Program

UN Development

Program

Table 1: Indices, Dimensions, Indicators \& Data Source

This study covers 14 economies from the CARICOM community. Appendix 1 provides a full list of the economies. It uses annual data from 2005 to 2017, which is the latest year for which all required data are available.

\subsection{Regression}

A regression analysis on the data was performed to indicate how much the revised human development index (GHDI) was explained. The following hypotheses were tested:

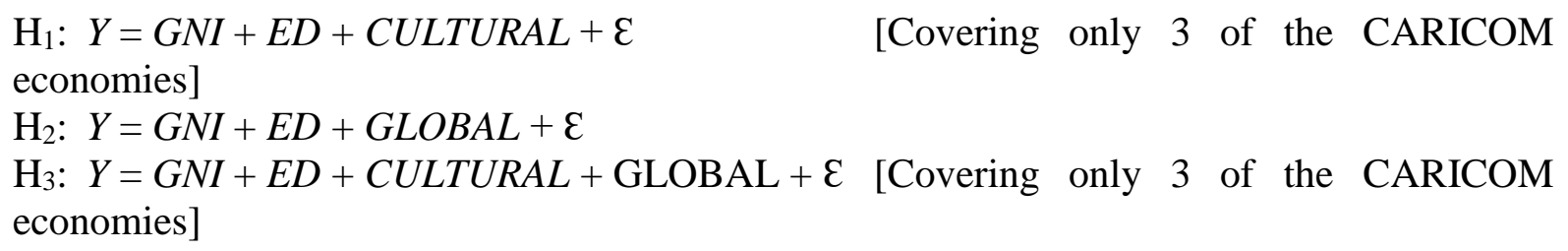

Where $Y$ is the GHDI

The evaluation of the three hypotheses follows the stepwise regression procedure as only a modest-sized set of independent variables is used (Semal et al, 2008) starting with $\mathrm{H}_{1}$ and ending with $\mathrm{H}_{3}$ that has the most independent variables. 


\section{Results}

\begin{tabular}{|c|c|c|c|c|c|c|c|c|}
\hline & $n$ & Variable & $\begin{array}{l}\text { Coefficien } \\
t\end{array}$ & Intersect & p-Value & $\mathbf{r}^{2}$ & $\begin{array}{l}\text { Stand } \\
\text { Error }\end{array}$ & $\begin{array}{l}\text { Based on } \\
\text { the p-Value }\end{array}$ \\
\hline \multirow[t]{4}{*}{$\mathrm{H}_{1}$} & 39 & & & 0.37925 & & $\begin{array}{r}0.9930 \\
1\end{array}$ & $\begin{array}{r}0.0051 \\
3\end{array}$ & Accepted \\
\hline & & GNI & $3.47 \times 10^{-6}$ & & $\begin{array}{r}9.33 \times 10^{-} \\
18\end{array}$ & & & Highly Sig \\
\hline & & $E D$ & 0.46424 & & $\begin{array}{r}1.17 \times 10^{-} \\
12\end{array}$ & & & Highly Sig \\
\hline & & $\begin{array}{l}\text { CULTUR } \\
A L\end{array}$ & -0.05666 & & $9.74 \times 10^{-7}$ & & & Highly Sig \\
\hline \multirow[t]{4}{*}{$\mathrm{H}_{2}$} & $\begin{array}{l}18 \\
2\end{array}$ & & & 0.20959 & & $\begin{array}{r}0.9349 \\
1\end{array}$ & $\begin{array}{r}0.0206 \\
6\end{array}$ & Rejected \\
\hline & & GNI & $2.77 \times 10^{-6}$ & & $9.5 \times 10^{-26}$ & & & Highly Sig \\
\hline & & $E D$ & 0.75194 & & $\begin{array}{r}2.59 \times 10^{-} \\
60\end{array}$ & & & Highly Sig \\
\hline & & $G L O B A L$ & -0.00028 & & 0.43180 & & & Not Sig \\
\hline \multirow[t]{5}{*}{$\mathrm{H}_{3}$} & 39 & & & 0.37452 & & $\begin{array}{r}0.9930 \\
2\end{array}$ & $\begin{array}{r}0.0052 \\
0\end{array}$ & Rejected \\
\hline & & GNI & $3.46 \times 10^{-6}$ & & $\begin{array}{r}4.56 \times 10^{-} \\
17\end{array}$ & & & Highly Sig \\
\hline & & $E D$ & 0.45776 & & $\begin{array}{r}2.69 \times 10^{-} \\
10\end{array}$ & & & Highly Sig \\
\hline & & GLOBAL & 0.00014 & & 0.81916 & & & Not Sig \\
\hline & & $\begin{array}{l}\text { CULTUR } \\
A L\end{array}$ & -0.05459 & & 0.00022 & & & Sig \\
\hline
\end{tabular}

Table 2 - Regression Results

As shown in Table 2, there is strong statistical evidence to support all three (3) hypotheses $\left[\mathrm{H}_{1}\right.$ $\mathrm{r}^{2}=0.99, \mathrm{H}_{2} \mathrm{r}^{2}=0.93$ and $\left.\mathrm{H}_{3} \mathrm{r}^{2}=0.99\right]$. For all three hypotheses also, the indices of GNI (gross national income per capita) and education are very highly significant with $\mathrm{H}_{2}$ at $9.50 \times 10^{-26}$ and $2.59 \times 10^{-60}$ the strongest respectively. This suggest human development in the CARICOM region is explained by the two indices. As shown for $\mathrm{H}_{2}$ and $\mathrm{H}_{3}$, the index of globalization has little or no significance statistically.

The index of cultural diversity has shown very strong significance statistically of $9.74 \times 10^{-7}$ and 0.00022 for $\mathrm{H}_{1}$ and $\mathrm{H}_{3}$ respectively. This suggest the index is a significant contributor to human development in the region.

Given that the globalization index in $\mathrm{H}_{2}$ and in $\mathrm{H}_{3}$ fail to be a contributory factor, we reject both hypotheses. $\mathrm{H}_{1}$ is accepted hence the revised human development index proposed is:

$$
\mathrm{GHDI}=0.37925+3.47 \times 10^{-6} G N I+0.46424 E D-0.05666 C U L T U R A L
$$


This function best predicts the revised HDI based on the linear combination of gross national income per capita (GNI), the education index (ED) and the cultural diversity index (CULTURAL). Result indicates, first, that the intercept is 0.379 representing the geometric mean of normalized indices for each of the three dimensions (ED, GNI and CULTURAL) when all the dimensions have a value of zero. Holding ED and CULTURAL constant, GHDI increases by $3.47 \times 10^{-6}$ for each additional GNI. Holding GNI and CULTURAL constant, GHDI increases by 0.4742 for each additional ED and holding GNI and ED constant, GHDI decreases by 0.567 for each additional CULTURAL. The p-values for all three coefficients are very significant statistically $(\mathrm{p}<0.001)$.

\section{Discussion \& Implications}

The purpose of this study was to validate a proposed three pronged quantitative model of a revised human development index for the economies of CARICOM. The study aimed to investigate in addition to the indices and explanatory variables of education and gross national income per capita, if the variables globalization and cultural diversity can be used to help explain the region's human development individually and/or in combination, and if so, by how much are their individual contributions.

The results of the regression analysis failed to show strong overall statistical evidence to support all three hypotheses $\left(\mathrm{H}_{1}, \mathrm{H}_{2}\right.$ and $\left.\mathrm{H}_{3}\right) . \mathrm{H}_{2}$ and $\mathrm{H}_{3}$ while demonstrating to be very strong models, were however rejected. The analysis also showed that the globalization variable was not significant enough individually nor in combination with the cultural diversity variable to contribute to the model. The analysis however showed an overall support for $\mathrm{H}_{1}$ with the variable of cultural diversity the strongest in the model. The cultural diversity variable was even very strong in the rejected $\mathrm{H}_{3}$ hypotheses. The findings therefore suggest globalization variable has absolutely had no statistical relationship with human development in the CARICOM economies during the period 2005 - 2017 while cultural diversity was a significant contributory factor during the same period in the building of human capital in the region along with the variables education and gross national income per capita.

A subsequent examination of the cultural diversity index (CDI) data was conducted to understand its characteristics of the cultural fractionalization labels assigned to the economies. The three CARICOM economies (Appendix 1) studied with $\mathrm{H}_{1}$ and $\mathrm{H}_{3}$ are:

Trinidad \& Tobago (CDI or cultural fractionalization of 0.38 )

Guyana (CDI of 0.46)

Jamaica (CDI of 0.027)

In calculating the cultural fractionalizations, Fearon (2003) took into account the cultural distances between ethnic groups inside each economy mostly considering linguistic differences. Other distances considerations were religion and customs.

Cultural backgrounds of learners are significant because ethnic, racial, linguistic, social, religious or economic differences can cause cultural disconnection leading corruption of motivation to learning. On the other hand, education inevitably brings shifts, however, learners' cultural identity plays a significant role in transmission of such values (Altugan, 2015). Therefore, the $\mathrm{H}_{1}$ results have implications for educators and policy makers engaged in or 
concerned with human development in the CARICOM region. Educators should be developing a deeper intercultural understanding to ensure effective learning outcomes especially as internal migration into capital cities intensifies.

\section{Conclusion}

The research reported here tries to do a better job of measuring human development in the CARICOM region than is available in the literature considering the key factors of globalization and cultural diversity.

The human development index is an aggregate index of human development level in an economy, measuring the economy's achievement in terms of health, education and actual income of its citizens (Yakunina, 2015). The revised human development index excluded the health component but introduced the variables of globalization and cultural diversity for studying. It can be concluded that the accepted proposed regression model of the components of the revised human development index for economies in the region is valid and reliable. The variable of globalization showed little or no statistical relationship to human development in the region so was not used in the final model, however the variable of cultural diversity was demonstrated to be a significant contributor to the human development. Our research suggests recommendations for educators and policy makers responsible for human development in the region, its findings contribute to current literature on human development considering cultural diversity.

This study has some limitations. First, the sample size (of only three CARICOM economies) was unavoidably small for the assessment of the cultural diversity. The cultural diversity labels were not available in Fearon (2003) for the other eleven economies. Future research should seek to extend the data considering the ethnic groups, languages, religion and customs in the remaining CARICOM economies. Second, the human development index has a general limitation. What is measured as HDI in one of the developing countries in CARICOM can be different from what is measured in any one of the other developing countries in region. So it may not be practical to generalize the results.

\section{Acknowledgment}

This research was undertaken as part of the $\mathrm{PhD}$ in E-research and Technology Enhanced Learning in the Department of Educational Research at Lancaster University. I am pleased to acknowledge the contribution of tutors and peers in supporting the development of this study and its report as an assignment paper.

\section{References}

Acemoglu, D., Johnson, S., Robinson, J. A. (2001). The Colonial Origins of Comparative Development: An Empirical Investigation. American Economic Review 91(5): 1369401.

Ambuj D. Sagar, A. D, Najam, A (1998). The human development index: a critical review. Ecological Economics

Bacsi, Z. (2017). Does Ethnic or Cultural Homogeneity Increase Economic Performance or Living Standards? Research Gate. 
Bárcena, A. (2018). Economic Commission for Latin America and the Caribbean (ECLAC), The Caribbean Outlook

Bisram, V. (2015). Impact of Ethnic Conflict on Development: A Case Study of Guyana. CUNY Academic Works.

Briguglio, L. (2018b). Handbook of small states: Economic, social and environmental issues. Routledge.

Briguglio, L. P. (2016). Exposure to external shocks and economic resilience of countries: evidence from global indicators. Journal of Economic Studies, 43(6), 1057-1078.

Brissett, N. (2018). Education for Social Transformation (EST) in the Caribbean: A Postcolonial Perspective. Education Sciences

Bruhn, M., Gallego, F. A (2012). Good, Bad, and Ugly Colonial Activities: Do They Matter for Economic Development? The Review of Economics and Statistics 94(2): 433-61

Churchill, S. A., Madhoo, Y. N., Nath, S. (2020). Ethnic Diversity and Human Capital Development in India: A disaggregated analysis at the state and district levels. Applied Economics

Dippel, C., Khadan, J. (2018). Colonization and Institutions in the Caribbean. Nuturing Institutions for a Resilient Caribbean (Inter-American Development Bank)

Fearon, J. D. (2003). Ethnic and Cultural Diversity by Country. Journal of Economic Growth, $8,195-222$

Gygli, S., Haelg, F., Sturm, J. (2018). The KOF Globalisation Index - Revisited. KOF Swiss Economic Institute

Herbert, S (2019). Development characteristics of Small Island Developing States. Knowledge, evidence and learning for development.

Huh, H., Park, C. (2019). A New Index of Globalization: Measuring Impacts of Integration on Economic Growth and Income Inequality. ADB Economics Working Paper Series No. 587

James, V., Gonzales, A. (2012). Development paths in the Caribbean. United Nations

Jules, D (2001). Development of a Caricom Strategic Plan for Primary and Secondary Education Services in the Caricom Single Market and Economy. The University of the West Indies.

Kim, H. (2014). Regionalism, Globalization, and Economic Development of the World. Globalistics and Globalization Studies 143-153

Kovacevic, M. (2019). Human Development Index: Concepts and Measurements, Project LINK meeting, Glen Cove, NY, 17-19 June, 2019

Künzel, V., Eckstein, D., Schäfer, L. (2018). Global Climate Risk Index 2018: Who Suffers Most From Extreme Weather Events? Weather-related Loss Events in 2016 and 1997 to 2016. BRIEFING PAPER. Germanwatch e.V.

Lyare, S., Francis, B. (2006). Education and development in the caribbean: a cointegration and causality approach. Economics Bulletin, Vol. 15, No. 2 pp. 1-13

McLetchie, A. (2013). The Parasitic Oligarchy? The Elites in Trinidad and Tobago. University of South Carolina. Doctoral dissertation.

Michalopoulos, S., Papaioannou, E. (2013). Pre-Colonial Ethnic Institutions and Contemporary African Development. Econometrica 81(1):113-52.

Migge, B., Léglise, I., Angela Bartens, A. (2010). Creoles in Education. A Discussion of Pertinent Issues. John Benjamins, pp.1-30, 2010

Muhammad, S. D, Majeed, S., Hussain, A. (2010). Impact of Globalization on HDI (Human Development Index): Case Study of Pakistan. European Journal of Social Sciences Volume 13, Number 1 (2010) 46 
Narayana, M. R. (2006). Measurement of education achievement in human development: Evidence from India. International Education Journal, 85-97.

Ocampo, J. A. (2012). Globalization and development. United Nations OECD (2018), Making Development Co-operation Work for Small Island Developing States, OECD Publishing, Paris

Palanivel, T. (2018). Small Island Developing States. A summary of the State of Human Development. Based on Human Development Indices and Indicators: 2018

Premdas, R. R. (1995). Ethnicity and Identity in the Caribbean: Decentering a Myth. Kellogg Institute

Premdas, R. R. (2011). Identity, ethnicity, and the Caribbean homeland in an era of globalization. Social Identities

Sabi, M. (2007). Globalization and Human Development. International Conference on Globalization and Its Discontents, Cortland, 2007

Samal, A. R, Fifarek, R. (2008). Backward elimination procedure for a predictive model gold concentration. Journal of Geochemical Exploration.

Ullaha, S., Azimb, P. (2017). Human Development in the Era of Globalization: An Asian Perspective. The Pakistan Journal of Social Issues (Volume VIII)

Yakunina, R. P, Bychkov, G. A (2015). Correlation on Applied Economics, ICOAE 2015, Kazan, Russia 


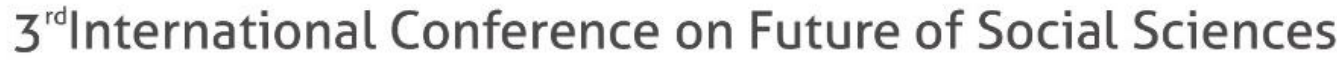

\section{Appendix}

Appendix 1 - CARICOM Members

\begin{tabular}{|c|c|c|c|c|c|}
\hline & Member & Population & $\begin{array}{l}\text { Official } \\
\text { Language }\end{array}$ & Spoken Languages & $\begin{array}{c}\text { Cultural } \\
\text { Diversity } \\
\text { Index } \\
\text { (Fearon, } \\
\text { 2003) } \\
\end{array}$ \\
\hline 1. & $\begin{array}{l}\text { Antigua and } \\
\text { Barbuda }\end{array}$ & 66,970 & English & $\begin{array}{l}\text { English, Antiguan Creole English, } \\
\text { Spanish (immigrants) }\end{array}$ & \\
\hline 2. & Bahamas & 303,611 & English & $\begin{array}{l}\text { English, Bahamian Creole, Haitian } \\
\text { Creole (immigrants), Spanish } \\
\text { (immigrants), Chinese (immigrants) }\end{array}$ & \\
\hline 3. & Barbados & 275,330 & English & English, Bajan Creole & \\
\hline 4. & Belize & & English & $\begin{array}{c}\text { Creole patois, and many Belizeans } \\
\text { are multilingual. Yucatec, Mopán } \\
\text { and Kekchí }\end{array}$ & \\
\hline 5. & Dominica & 70,786 & English & $\begin{array}{c}\text { English, Antillean Creole French, } \\
\text { French, Haitian Creole } \\
\text { (immigrants) }\end{array}$ & \\
\hline 6. & Grenada & 89,227 & English & $\begin{array}{l}\text { English, Grenadian Creole English, } \\
\text { Antillean Creole French }\end{array}$ & \\
\hline 7. & Guyana & 747,884 & English & $\begin{array}{c}\text { English, Guyanese Creole, } \\
\text { Guyanese Hindustani (Hindi-Urdu), } \\
\text { Spanish }\end{array}$ & 0.46 \\
\hline 8. & Haiti & $6,964,549$ & $\begin{array}{l}\text { French, } \\
\text { Creole }\end{array}$ & French, Haitian Creole & \\
\hline 9. & Jamaica & $2,665,636$ & English & $\begin{array}{c}\text { English, Jamaican Patois, Spanish, } \\
\text { Caribbean Hindustani, Irish, } \\
\text { Chinese }\end{array}$ & 0.027 \\
\hline 10. & $\begin{array}{l}\text { St. Kitts \& } \\
\text { Nevis }\end{array}$ & 38,756 & English & $\begin{array}{c}\text { English, Saint Kitts and Nevis } \\
\text { Creole English, Spanish } \\
\text { (immigrants) }\end{array}$ & \\
\hline 11. & St. Lucia & 158,178 & English & $\begin{array}{l}\text { English, Saint Lucian Creole } \\
\text { French, French }\end{array}$ & \\
\hline 12. & $\begin{array}{l}\text { St. Vincent } \\
\quad \& \text { the } \\
\text { Grenadines }\end{array}$ & 115,942 & English & $\begin{array}{l}\text { English, Vincentian Creole English, } \\
\text { Antillean Creole French }\end{array}$ & \\
\hline 13. & Suriname & 541,638 & Dutch & $\begin{array}{c}\text { Dutch, Sranan Tongo, Sarnami } \\
\text { Hindustani (Hindi-Urdu), Javanese, } \\
\text { Ndyuka, Saramaccan }\end{array}$ & \\
\hline 14. & $\begin{array}{l}\text { Trinidad \& } \\
\text { Tobago }\end{array}$ & $1,169,682$ & English & $\begin{array}{c}\text { English, Trinidadian Creole, } \\
\text { Tobagonian Creole, Trinidadian } \\
\text { Hindustani (Hindi-Urdu), Spanish }\end{array}$ & 0.38 \\
\hline
\end{tabular}

